\title{
A Decade of Treatment of Canine Parvovirus in an Animal Shelter: A Retrospective Study
}

\author{
Kevin Horecka * (1), Steve Porter, E. Susan Amirian (1) and Ellen Jefferson \\ Research Department, Austin Pets Alive!, Austin, TX 78703, USA; steve.porter@austinpetsalive.org (S.P.); \\ ea25@rice.edu (E.S.A.); ellen.jefferson@austinpetsalive.org (E.J.) \\ * Correspondence: kevin.horecka@gmail.com
}

Received: 26 April 2020; Accepted: 24 May 2020; Published: 29 May 2020

Simple Summary: The canine parvovirus (CPV) is a highly contagious gastrointestinal disease which affects unvaccinated, insufficiently vaccinated, or improperly vaccinated dogs and results in a fatality rate greater than $90 \%$ if left untreated. Treatment in private practice settings can often cost several thousand dollars, making it an unaffordable option for many pet owners as well as a challenging population to treat for shelters. Here, we examine 11.5 years of data from Austin Pets Alive!, a private animal shelter in Austin, TX, which has treated 5127 dogs infected with CPV since 2008. We show an $86.6 \%$ ( $n=4438 / 5127)$ survival rate, with the most critical period of treatment during the first five days of care, and detail the protocols used to achieve this high proportion of successful treatment outcomes. A CPV season was observed peaking in May and June and accounting for as much as a $41 \mathrm{animal} / \mathrm{month}$ increase compared to low periods in August, September, December, and January. Low-weight animals and male animals were found to be at higher risk for mortality. Together, these results aim to assist shelters in creating programs to treat this disease and to inspire future research into improving practices in treatment and prevention.

\begin{abstract}
Here, we present 11.5 years of monthly treatment statistics showing an overall intake of 5127 infected dogs between June 2008 and December 2019, as well as more detailed datasets from more recent, less protracted time periods for the examination of mortality risk, seasonality, and resource requirements in the mass treatment of canine parvovirus (CPV) in a private animal shelter. The total survival rate of animals during the study period was $86.6 \%$ ( $n=4438 / 5127 \mathrm{dogs}$ survived) with the probability of survival increasing to $96.7 \%$ after five days of treatment (with $80 \%$ of fatalities occurring in that period). A distinct parvovirus season peaking in May and June and troughing in August, September, December, and January was observed, which could have contributed as much as 41 animals peak-to-trough in the monthly population (with a potential, smaller season occurring in October). Low-weight and male animals were at higher risk for death, whereas age was not a significant contributing factor. Treatment time averaged $9.03 \mathrm{~h}$ of total care during a seven-day median treatment duration. These findings, taken together, demonstrate that canine parvovirus can be successfully treated in a sustainable manner within a shelter setting using a largely volunteer workforce.
\end{abstract}

Keywords: canine parvovirus; animal sheltering; treatment; veterinary epidemiology; survival analysis

\section{Introduction}

Canine parvovirus $(\mathrm{CPV})$ is a highly contagious and relatively common virus that causes substantial morbidity and mortality in dogs worldwide [1,2]. Symptoms include acute enteritis, fever, and potential cardiac sequelae (i.e., myocarditis and myocardial fibrosis), with the most clinically severe disease manifesting (i.e., sepsis and severe dehydration) among dogs infected between six weeks and six 
months of age [2,3]. Survival rates are dependent upon treatment, with estimates ranging from $9 \%$ in untreated populations up to $80 \%-90 \%$ in tertiary care centers $[2,4,5]$. In private practice settings, the cost of treatment can be $\$ 1000$ to $\$ 2000$ (USD), indicating that financial constraints may be a factor in disease-related euthanasia [6,7].

Rather than providing treatment, nonprofit rescues and shelters may often opt to euthanize infected dogs, both due to financial constraints and as a potential disease control tactic, given the highly contagious nature of the illness. Austin Pets Alive! (APA!), a nonprofit, private shelter in Austin, Texas, espouses the philosophy of saving the animals most at risk for euthanasia for treatable/manageable conditions (a so-called, No Kill philosophy) [8-11]. Since 2008, APA! has implemented a protocol to treat CPV-infected dogs in a quarantine environment [12], averaging several hundred dogs a year. CPV-infected dogs are treated within a section of the shelter exclusively designated for the treatment of parvovirus with the support of volunteers and donations, which, along with optimized mass treatment protocols and procedures, aids in reducing costs to a reported average of between \$56 and \$300 USD (depending on the precise method of calculation; i.e., the inclusion of volunteer time and days on site in cost estimates) $[13,14]$ and approximately $9 \mathrm{~h}$ of volunteer time per animal.

Treatment for CPV in this study varied somewhat based on symptom presence and severity, animal weight (with $5 \mathrm{lbs}$ or $2.27 \mathrm{~kg}$ used as a threshold as decided by Veterinary staff), and the result of the most recent CPV test. Although almost all animals in the intensive care unit (ICU) test positive at intake, additional protocols are present for critically exposed animals (i.e., members of a litter whose siblings, with which they are cohoused, show symptoms) that would have been euthanized at their originating shelter but have yet to present symptoms or otherwise tested negative. These negative tests may contradict prior evidence from the originating shelter (i.e., a prior positive test). An exposed treatment (ET; described in Appendix A) was implemented until these animals presented with symptoms (or, until they pass a five-day hold and show two consecutive solid stools along with an additional negative test, which is required of all animals leaving the ICU). More symptomatically severe or at-risk animals were given intravenous (IV) treatments (a more time-consuming treatment protocol which is more difficult to implement with healthy animals as they are more likely to remove their IV catheters), while less symptomatically severe and lower-risk animals were given subcutaneous (SQ) treatments. These treatments were subject to change given changing status of the animal during its stay. Additionally, it is important to note that all animals had unknown vaccination statuses and were generally assumed to be unvaccinated, improperly vaccinated, or to have undergone incomplete vaccination courses.

To our knowledge, Austin Pets Alive! has treated more dogs with CPV than any other organization listed in the bibliography, and, as such, is among the largest samples of this population in the world. Given this experience in CPV treatment, an examination of its protocols, success rates, signalments, seasonality trends, and resource usages is warranted, providing vital data that can inform the development of guidelines for in-shelter CPV treatment and management. In the present study, we review the 11.5 years of history of this innovative treatment program using four data sets, with increasing temporal and feature resolution, which have been gathered as the data collection practices of the shelter have improved. Taken together, this work strongly supports the assertion that canine parvovirus is an imminently treatable condition, even in persistently resource-restricted environments.

\section{Materials and Methods}

Data in this study are sourced from four data sets (see Table 1 for a summary) as the data collection methods of the shelter improved over time. Initially (2008-2013), APA! collected data only in month-by-month aggregates, as is common for newer shelters with limited resources, and this collection continued through 2019 such that Monthly Aggregate data $(\mathrm{N}=5127)$ was available from 2008-2019. Additionally, in 2013, an End-of-Shift Report (N days = 2474) was created that then allowed volunteers and, eventually, staff to enumerate the animals treated, their condition, the hours per 
treatment shift, and the number of volunteers and staff that participated in treatment. These data are still being collected at the time of publication. In 2016, data on specific animals, including their signalment information such as weight, sex, approximate age, and specific intake dates, became available; these data are also still being collected as of the time of publication. Finally, treatment-level data (i.e., collected during twice a day treatment; see the treatment protocols in Appendix A for more information) is present for animals from a specific time period of January 2017 through January 2018.

Table 1. The data sets, time ranges, and temporal resolutions for the four data sets examined in this study.

\begin{tabular}{lccc}
\hline \multicolumn{1}{c}{ Data Set } & Date Range & Resolution & Dogs (N) \\
\hline A. Monthly Aggregate & $2008-2019$ & Survived/Died Populations & 5127 \\
B. End-of-Shift Reports & $2013-2020$ & Daily Population/Staffing & N/A (2474 days) \\
C. Animal Records & $2016-2020$ & Individual Animals & 1957 \\
D. Treatment Records & $2017-2018$ & Twice-Daily Treatments Per Animal & 589 \\
\hline
\end{tabular}

The following statistical analyses (Table 2, right column) were used to examine key questions (Table 2, left column) in regard to the data sets (Table 2, middle column. The Python [15] language was used with critical libraries including SciPy [16,17], NumPy [18,19], Pandas [20], Scikit-Posthocs [21], Lifelines [22], Matplotlib/Seaborn [23,24], and FBProphet [25].

Table 2. Key questions, their associated data sets, and statistical methods employed. An explanation of what each test is used for is provided for convenience.

\begin{tabular}{|c|c|c|c|c|}
\hline & Question & Data Set(s) Used & Statistical Analysis & Statistical Analysis Description \\
\hline 1. & $\begin{array}{l}\text { What is the expected distribution } \\
\text { of survival rates when treating } \\
\text { canine parvovirus (CPV)? }\end{array}$ & A & $\begin{array}{l}\text { Descriptive Statistics, } \\
\text { Kolmogorov-Smirnov test [26], } \\
\text { Gumbel distribution fit [27], }\end{array}$ & $\begin{array}{l}\text { KS test is used for goodness-of-fit of } \\
\text { different distributions (like Gumbel) }\end{array}$ \\
\hline 2. & $\begin{array}{l}\text { How likely is survival after each } \\
\text { day of treatment? }\end{array}$ & $\mathrm{D}$ & $\begin{array}{l}\text { Kaplan-Meier Curve Estimation } \\
{[28,29]}\end{array}$ & KM Curves describe survival over time \\
\hline 3. & $\begin{array}{l}\text { Is there evidence for a relationship } \\
\text { between the number of } \\
\text { CPV-infected dogs being treated } \\
\text { and their survival rate? }\end{array}$ & A & Linear Regression & $\begin{array}{l}\text { Linear regression examines simple } \\
\text { linear relationships between variables }\end{array}$ \\
\hline 4 . & $\begin{array}{l}\text { Is there evidence for seasonal } \\
\text { trends in the number of } \\
\text { CPV-infected dogs in the shelter } \\
\text { each month? }\end{array}$ & A, B & $\begin{array}{l}\text { Kruskal-Wallis H-test [30] and } \\
\text { Dunn's test, Fourier Coefficient } \\
\text { Forecast Model (FBProphet) [25] }\end{array}$ & $\begin{array}{l}\text { KW and Dunn's examine the } \\
\text { hypothesis of monthly differences, } \\
\text { FBProphet quantifies seasonal effects }\end{array}$ \\
\hline 5. & $\begin{array}{l}\text { Is there evidence for signalment } \\
\text { variables influencing the survival } \\
\text { rate for subpopulations of } \\
\text { CPV-infected dogs (i.e., age, } \\
\text { weight, and sex)? }\end{array}$ & C, D & Welch's T-Test, and Fisher's Exact Test & $\begin{array}{l}\text { T-Test and Fisher's Exact directly } \\
\text { compare outcomes for variables of } \\
\text { interest }\end{array}$ \\
\hline 6. & $\begin{array}{l}\text { How many days should } \\
\text { CPV-infected dogs be expected to } \\
\text { require treatment? How many } \\
\text { hours of care does this translate to } \\
\text { for staff or volunteers? }\end{array}$ & $\mathrm{B}, \mathrm{D}$ & $\begin{array}{l}\text { Descriptive Statistics, Linear } \\
\text { Regression }\end{array}$ & $\begin{array}{l}\text { Linear regression examines simple } \\
\text { linear relationships between variables }\end{array}$ \\
\hline
\end{tabular}

Wherever possible, descriptive statistics (sample size, mean, and/or median) were examined. Kolmogorov-Smirnov test for goodness of fit as well as Anderson-Darling test were used to examine normal and Left-Gumbel distribution fits in the Monthly Aggregate ( $\mathrm{N}=127 ; 2008-2019)$ and Treatment Records (N = 589; 2017-2018) data while a Kaplan-Meier curve was used to examine survival over time in the Treatment Records data. Although it might normally be preferable to perform a one-way ANOVA for detection of seasonal variation, assumptions of normality of residuals (as tested via a Shapiro-Wilk test) and homogeneity of variance (as tested via Brown-Forsythe) revealed that this test would be inappropriate. As a result, a Kruskal-Wallis H-test, a nonparametric test for the population medians across months being equal, was employed. Additionally, although day-level resolution is present in the End-of-Shift Reports (N days $=2474 ; 2013-2020)$, these daily values will include duplicate animals and are, therefore, nonindependent. To correct for this, the twice a month median values of 
these days for each month were taken before performing analyses at the month level. This is somewhat conservative given the average length of stay is approximately seven days. This reduced the test variance, but substantially improved the independence of samples. Although more complex models could be used to assess the relationship of signalment variables (sex, weight, and age) to outcome, in this case, direct tests of these key signalment variables based on prior hypotheses (justified by prior work) are employed in an attempt to provide the most clarity into their relationship with survival.

A few noteworthy caveats exist within these data sets that deserve enumeration before examining the results of the analyses. Firstly, in the Monthly Aggregate data, data are missing for the months of April 2016 through December 2016 (though a year-level survival rate exists which matches the existing trends and can be used to assess the overall survival rate). This data loss was due to a change in shelter management platform software and is, therefore, not suspected to create unintended biases in the results. Secondly, the End-of-Shift Reports contain daily counts of numbers of animals present in the ICU, but these animals are not identified and, as such, special care must be taken in analyzing these data as day-to-day measurements are not independent. Thirdly, two major changes in treatment protocol occurred throughout this period: (1) the addition of Force Feeding as a part of the standard protocol occurred in December of 2016, and (2) the addition of high-dose IV Vitamin C was initiated in February 2018.

\section{Results}

As per the questions and analyses in Table 2, the results follow:

\subsection{Survivability}

\subsubsection{Overall Survival Rates}

In examining the survival rates, we primarily examined the distribution of survival rates on a monthly level as this data set spans the entire 11.5 years of operational history from 2008 to 2019 . There were four notable dips in survival such that the rate was less than $70 \%$ in a given month. Three of those were survival rates of $66.6 \%$, while one was $0 \%$ as only a single animal was present during that month and it did not survive treatment. Excluding the $0 \%$ outlier, the Kolmogorov-Smirnov test for goodness of fit of the data to a normal distribution was significant (rejecting the null hypothesis that the data is sampled from this distribution, i.e., the data is non-normal and "greater" than the normal distribution; $\mathrm{KS}=0.159, p=0.001$ ). As such, a Left-Gumbel distribution (selected via an Anderson-Darling test) [31] was fit to assess (KS $=0.066, p=0.317$, i.e., we fail to reject the null hypothesis and assume the data can be fit to this distribution) the descriptive statistics of the survival rates. These descriptions can be found in Figure 1. Note that although this analysis can be useful in understanding expected variability in this outcome measure, the critical statistic was not found via taking the means of the survival rates, but rather via taking the overall number of survived animals divided by the overall population $(4438 / 5127=86.6 \%)$. 


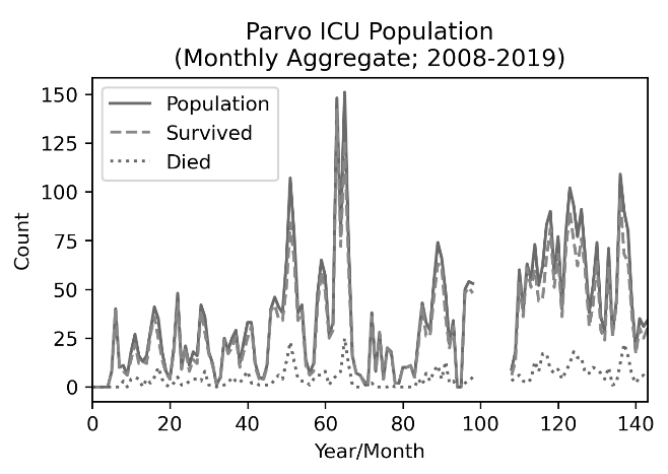

(a)

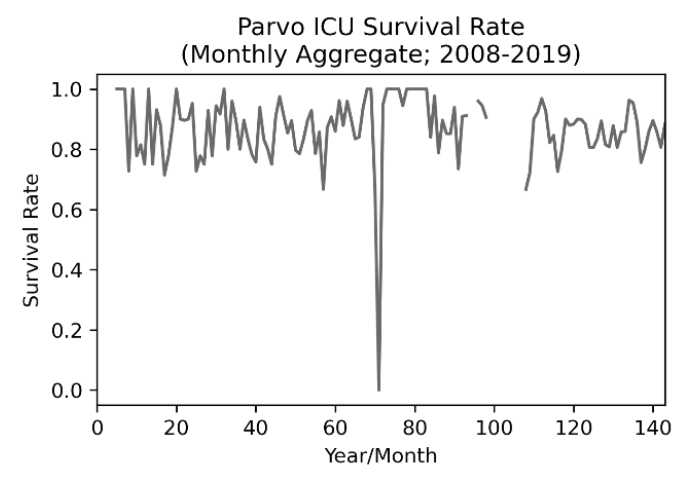

(b)

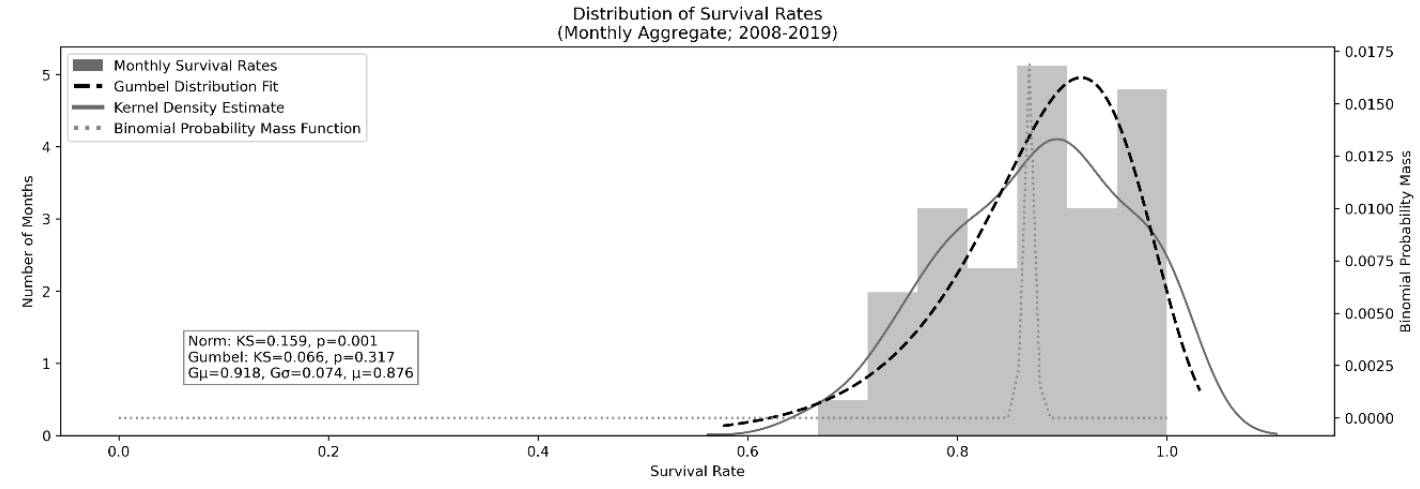

(c)

Figure 1. Population values (a), survival rates (b), and distributional properties (c) of canine parvovirus (CPV)-infected dogs from July 2008 to December 2019. The expected survival rates are approximately $86.6 \%$ and there is no evidence for a relationship to the overall population occupying the intesive care unit (ICU).

\subsubsection{Time Course of Survival}

We can examine the time course of survival (Figure 2) using the Treatment Records $(\mathrm{N}=589$; 2017-2018), primarily to illustrate how critical the first five days of treatment are for animals with CPV infections. If animals survive the first five days, the probability of survival increases from $85.6 \%$ on intake to the shelter to $96.7 \%$ after the 10 th treatment (end of day five). Note that the average overall length of stay is 14.33 treatments or just over seven days. The peak death rate occurs on the 7 th treatment and $80 \%$ of deaths are accounted for by the first 10 treatments (i.e., first five days).

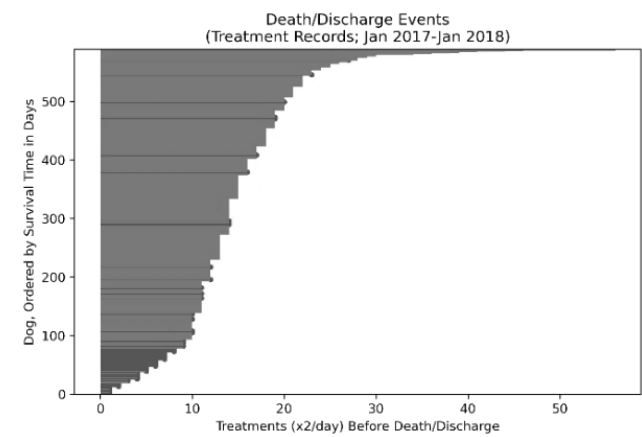

(a)

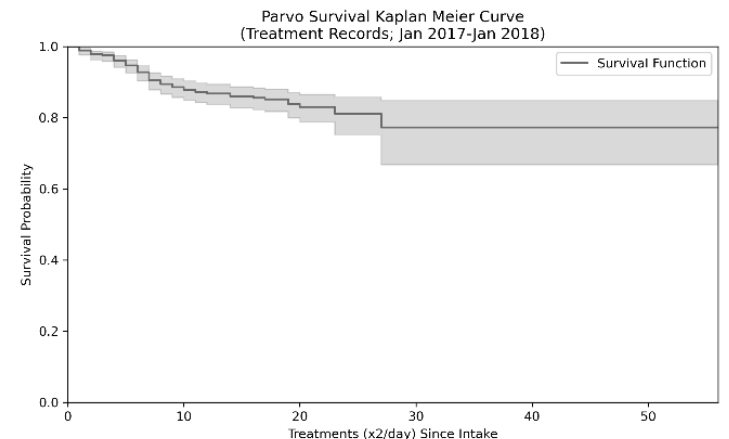

(b)

Figure 2. Cont. 


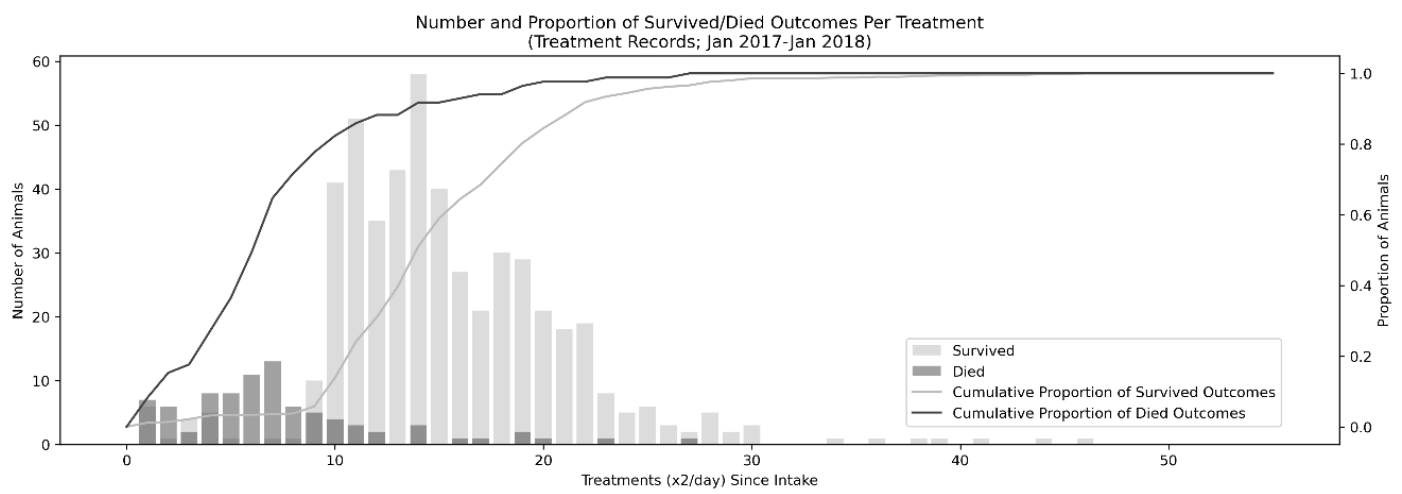

(c)

Figure 2. Event plot (a) and Kaplan-Meier curve (b) for survival over time (c) for Canine parvovirus (CPV)-infected dogs. Darker lines in the death/discharge events plot (a) represent animals who did not survive. Distribution of Survived and Died outcomes by treatment shift can be seen in panel (c) with $80 \%$ of deaths occurring on or before the 10 th treatment, which, at two treatments/day, is on the 5 th day.

\subsubsection{Symptomaticity}

The Treatment Records data $(\mathrm{N}=589 ; 2017-2018)$ is the only data set of the ones examined in this study with sufficient feature richness to be used to assess symptom severity. Within the 589 animals in the Treatment Records data, 574/589 (97.5\%) became symptomatic with CPV (where symptomaticity is defined as having one of: inappetence, vomiting, ill formed stool, diarrhea or bloody diarrhea, pale gum color, and lethargy or coma). Of the 15 asymptomatic patients, two were discharged early (after three and four treatments, respectively). Six were distemper-exposed animals that were held for longer durations. The remaining six were held for the typical duration due to extensive exposure to CPV positive animals. Of the 574 animals that were symptomatic of CPV, 230/574 (40\%) developed severe symptoms (where severe is defined as the presence of bloody diarrhea, six or more incidents of vomiting in a $12 \mathrm{~h}$ period, white or gray gums, and/or lethargy/coma). Of the $230 \mathrm{dogs}$ with severe symptoms, 70 (30.4\%) did not survive. For comparison, of the 344 dogs with milder symptoms, $15(4.4 \%)$ did not survive.

\subsubsection{Population Versus Survival Rates}

There was no evidence the overall Population is related to the Survival Rate ( $p=0.20 ; \mathrm{F}=1.692$ ). This indicates that as population increases/decreases, no corresponding increase/decrease was seen in survival.

\subsection{Seasonal Trends}

In order to assess seasonality within the data, we first examined if the population medians of all groups were equal across months in the Monthly Aggregate ( $\mathrm{N}=5127 ; 2008-2019)$ and End-of-Shift Report ( $N$ days $=2474 ; 2013-2020$ ) data sets (see Figure 3 for a visualization of distributions). Both data sets violated assumptions of normality of residuals ( $\mathrm{W}=0.95, p<0.001$ for Monthly Aggregate and $\mathrm{W}=0.90, p<0.001$ for End-of-Shift Report via Shapiro-Wilks) but not homogeneity of variance $(\mathrm{F}=1.06$, $p=0.40$ for Monthly Aggregate and F $=0.46, p=0.93$ for End-of-Shift Report via Brown-Forsythe). A Kruskal-Wallis H-test, a nonparametric test for the population medians being equal, was performed. Monthly Aggregates were significantly different from the median $(\mathrm{KW}=19.72, p=0.049)$ and End-of-Shift Report months were significantly different from the median $(\mathrm{KW}=29.32, p=0.002)$ suggesting there are month-over-month population differences. 


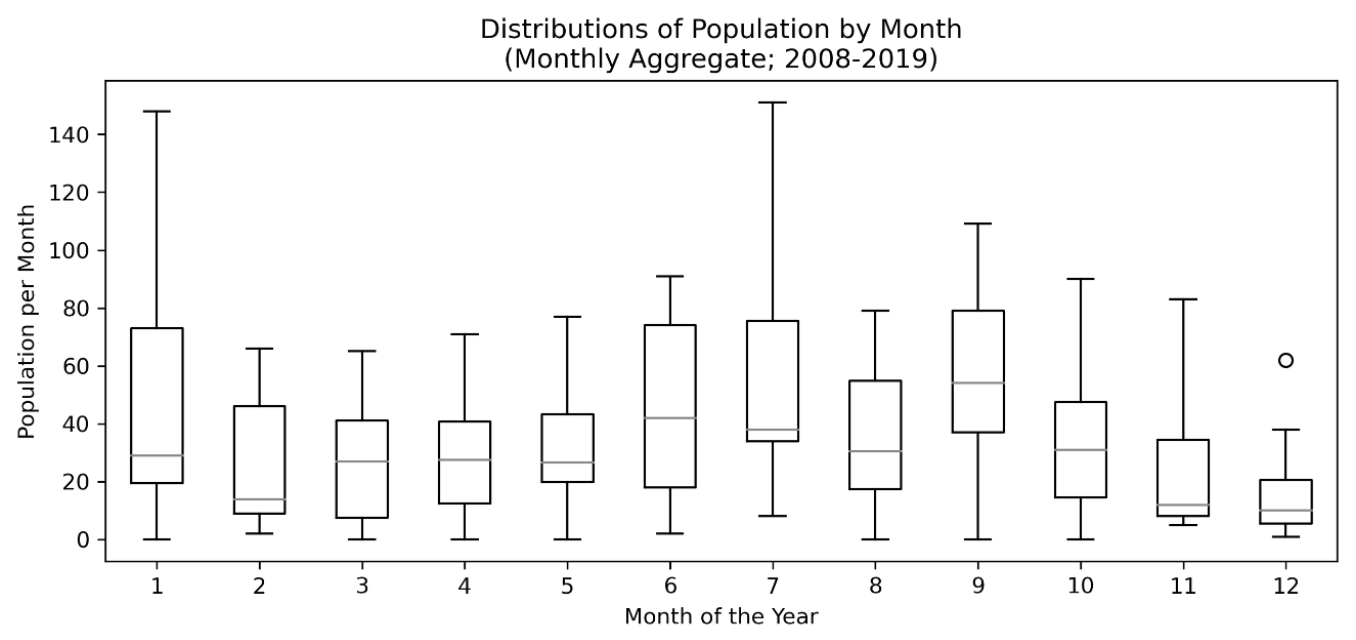

(a)

Distributions of Twice-Monthly Median Daily Population by Month (End-of-Shift Reports; 2013-2020)

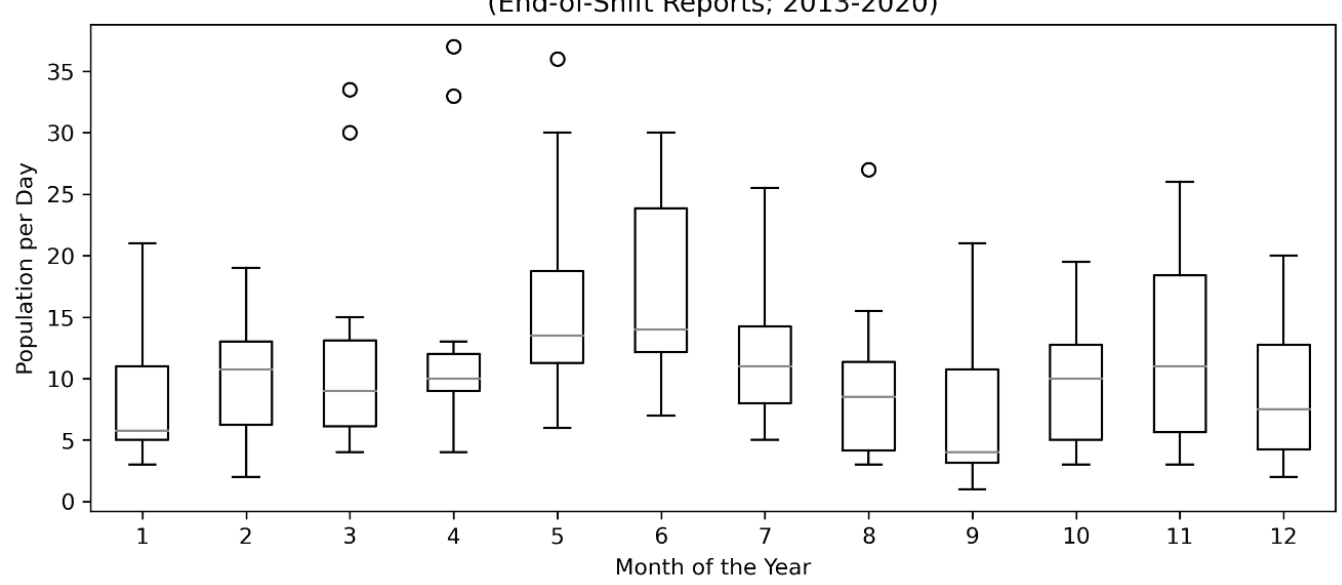

(b)

Figure 3. Box and whisker plots of Monthly Aggregate ( $N=5127 ; 2008-2019)$ (a) and End-of-Shift Report (N days $=2474 ; 2013-2020)($ b) data showing clear seasonal trends in the number of Canine parvovirus (CPV)-infected dogs peaking in the summer months. Circles indicate outlier points with interquartile range greater than 1.5 (i.e. Q3 + 1.5 $\times(\mathrm{Q} 3-\mathrm{Q} 1)$ for the upper bound).

Follow-up Dunn's test with False Discovery Rate correction revealed that May and June were the peak months when compared to January, December, August, and September $(p<0.05$ for all after FDR correction; see Figure 4 for details). All of this points to the idea that there was at least one peak CPV season in the summer (May-June) with a trough immediately after (September). These tests, however, were quite conservative.

To get more resolution on the effect, a follow-up Fourier Coefficients model was produced using the Monthly Aggregate data to examine the relative effect component sizes of a CPV season, as well as the nonstationarity of the population as the organization grew. Two models were trained with one and two coefficients (i.e., seasonal peaks), and the cross-validated mean absolute error (MAE) was compared for a 180 day period with up to a one-year horizon, 42 days was chosen as the benchmark horizon. The Mean Absolute Error was lower for the model with two coefficients (23.04 vs. 25.03 for a single-component model), suggesting it is a marginally better fit (i.e., a smaller, second CPV season may be present; see Figure 4). Both models produced yearly trend components with increases in population year-over-year accounting for four additional animals per month. The primary CPV season had a peak-to-peak interval of 41 animals. The interaction of these components was not directly examined. 


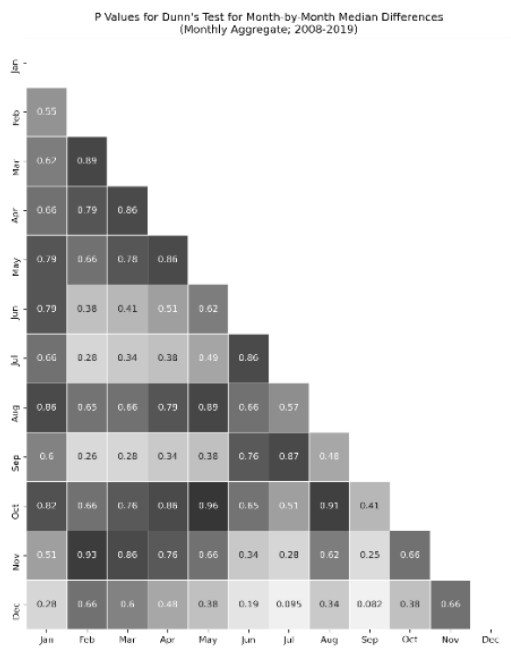

(a)

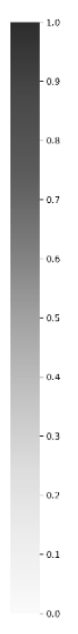

Forecast of Parvo IIU Population Over Time
(Monthly Aggregate; 2008-2019)

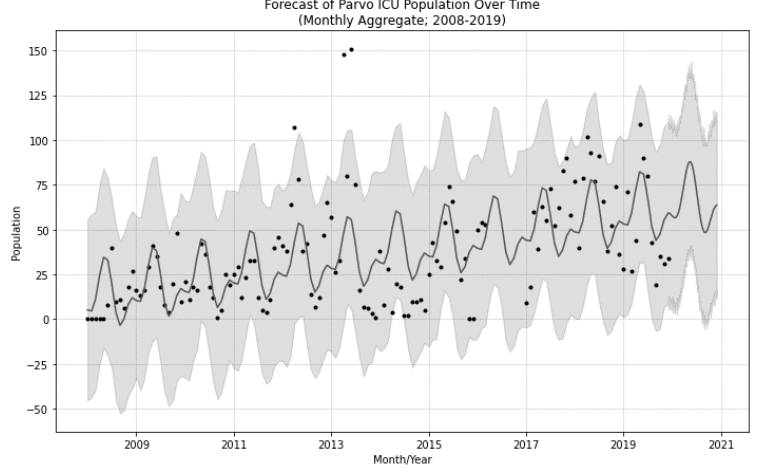

(c)

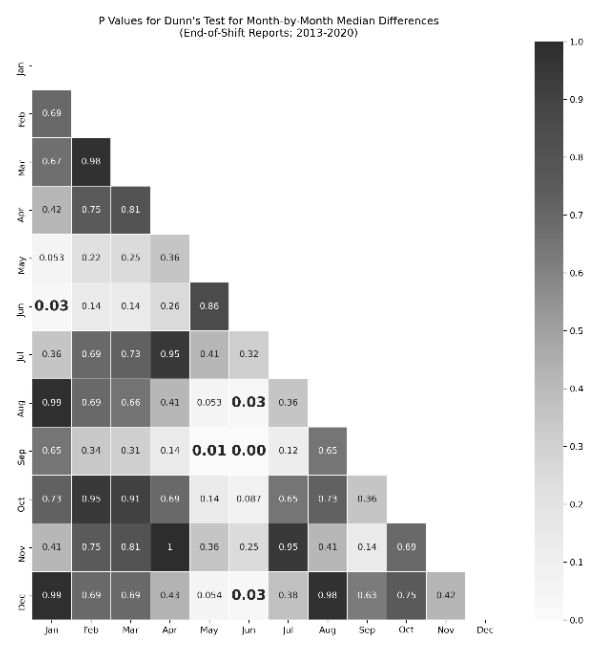

(b)

Figure 4. Heatmaps (a,b) of Dunn's test p-values (FDR corrected) for Monthly Aggregate ( $N=5127$; 2008-2019) (a) pairwise differences and End-of-Shift Report ( $\mathrm{N}$ days $=2474 ;$ 2013-2020) (b) pairwise differences from the monthly median canine parvovirus (CPV)-infected population. Bolded elements indicate statistical significance with alpha less than 0.05. Forecast visualization (c) from Fourier components model via FBProphet. Peaks can be observed in seasonality in May and June and troughs can be seen in January, August, and September. The overall population of CPV-infected dogs in the ICU increased at a rate of approximately four animals per month with a seasonal component accounting for approximately 41 dogs between peak and trough season.

\subsection{Signalment Variable Relationships}

Three key signalment variables were hypothesized to influence outcomes based on prior work: age, weight, and sex. Age and weight were examined directly in the Animal Records ( $\mathrm{N}=1957$; 2016-2020) data via a Welch's T-test and a significant effect of weight $(\mathrm{t}=-4.287, p<0.001, \mathrm{~d}=0.396)$ was found, but no significant effect of age $(t=0.815, p=0.415)$ was found. Note that weight was undefined for 444/1957 animals, and age was undefined for 7/1957. Sex was examined using a Fisher's exact test, and a significant effect of sex was found, with males dying more frequently at $(\mathrm{N}=210 / 931)$ $22.6 \%$ of the time and females dying $(\mathrm{N}=114 / 996) 14.0 \%$ of the time (see Table 3 for contingency table for this sample). Sex was undefined for 27/1957 animals.

Table 3. Contingency table for effect of sex on survival, with male dogs showing $22.6 \%$ more fatalities than female dogs as measured in the Animal Records data ( $\mathrm{N}=1957 ; 2016-2020)$.

\begin{tabular}{ccc}
\hline & Male & Female \\
\hline Survived & 721 & 882 \\
Died & 210 & 114 \\
\hline
\end{tabular}




\subsection{Capacity for Care}

Finally, in order to aid other organizations in implementing programs like the one discussed in this paper, we examined the amount of staff and volunteer time needed to treat animals in the ICU. We used the total number of animals divided by the shift time multiplied by the number of people on shift in the End-of-Shift Report ( $\mathrm{N}$ days $=2474 ; 2013-2020$ ) data to find a unimodal distribution with mean of $0.63 \mathrm{~h}$ per animal and median of $0.5 \mathrm{~h}$ per animal (See Figures A1 and A2 in Appendix B for distributions relevant to these analyses). When the mean time per treatment was multiplied by the mean number of treatments required for animals in the Treatment Data, we found animals required, on average, $9.03 \mathrm{~h}$ of treatment across the duration of their stay. As both of these distributions are skewed, the median treatment time was lower than the mean value.

\section{Discussion}

Although previous work has established effective treatment practices [32-34] and discussed the potential influence of signalment factors on survival [35-38], the implementation of CPV treatment programs has yet to become common practice for animal shelters (though some exceptions exist) $[39,40]$. Here, we present 11.5 years of CPV treatment with increasing feature resolution as well as the protocols for operation of a CPV ICU in an animal shelter setting (see details in Appendices A and C). We demonstrate an $86.6 \%$ survival rate $(4438 / 5127=86.6 \%)$, which is higher than many previous reports [4,41-43]. The most critical period for survival was the first five days, during which $80 \%$ of fatalities occurred, suggesting rapid care is needed in order to effectively treat CPV. A distinct seasonal trend, peaking in the summer in May and June and troughing in August, September, January, and December, suggesting the presence of a possible second, smaller CPV season in addition to the dominant, summer season which represented an approximately 41 animal peak-to-trough difference in population. Finally, low-weight animals and male animals were at higher risk of death than other populations.

It is worth noting that the variability in survival rate was surprisingly limited across the datasets evaluated here. In particular, when populations increase, one might expect a reduction in survival rate due to insufficient staffing or other resources, which reduce quality of care, but no evidence for such an effect is present in these data. Moreover, with a single anomalous exception, no single month had a survival rate below $66.6 \%$ despite the presence of large disaster events such as Hurricane Harvey [44] and the Bastrop Fires [45]. This survival rate was almost certainly biased upward when compared to an untreated survival rate of $9 \%[2,3]$, as many animals only developed mild symptoms (potentially due to maternal antibodies [46] or partial vaccination protection [47]); however, given that standard procedure at many shelters is to kill exposed animals, the effective survival rate of the population would be $0 \%$ in many shelters, regardless of their chances of surviving CPV itself. As the program has expanded (at a rate of approximately four additional animals per month), taking in animals from wider regions of Texas, the efficiency of a dedicated treatment ICU for CPV has become apparent. Future work should attempt to examine if different regions have similar incidence of the illness, seasonality, and signalment correlates of survival, as some of these effects could be specific to the Central Texas region.

Consistent with other work [36,48-51], the presence of one or two CPV seasons (with the larger peak occurring around May-June) can drastically impact the need for staffing and resources. Note that a second CPV season, though weakly supported by these data, was consistent with volunteer and staff reports. Despite our data showing no evidence for population-dependent changes in survival rate, a large (41-animal, peak to trough) swing in population strains staffing and can increase turnover. As a result, maintaining a large, well-trained volunteer organization was critical to stable operations (see Appendix C for more detail on this). The reason for the presence of a CPV season is, as of yet, unknown. Some work has examined wider relationships between disease spread in animal populations relative to factors such as temperature, rainfall, and resource availability [52,53], but no such examination has been conducted specifically for CPV. Attempts to perform this examination with the data in this study would require additional information about the sources of animals, which was 
not present in the data set and is beyond the scope of this study. Future work should examine potential natural and public-health drivers which might contribute to this seasonality. As CPV is so effective at surviving in the environment for extended durations [54], one might speculate that persistent reservoirs of the virus exist within the environment [55-57], to which unvaccinated, insufficiently vaccinated, or improperly vaccinated animals are being seasonally exposed (i.e., parks, rivers, or even animal shelters). Note that the authors have not seen a single case example of an animal in the custody of Austin Pets Alive! in the general shelter population breaking with CPV in the entire history of the organization, likely due to aggressive vaccination and quarantine procedures [58,59].

Three major factors were examined in this study that were hypothesized to relate to the survival probability include the time since intake, weight, and sex of the animal. These factors have been examined in previous work $[36,37,58]$. Though each illustrates important risk factors for CPV survival, time since intake, in particular, highlights the criticality of additional interventions being developed that can be implemented in the first few days after arrival at the shelter (with survival of the first five days increasing survival rate by $11.5 \%$ ). Many owners may wait until symptoms have progressed to the extreme (i.e., bloody diarrhea, lethargy, and severe vomiting), making the treatment less likely to be effective. Although some other work has also assessed the contribution of breed to survival [59], we were unable to assess relationships to breed in this study as the breeds of animals were entirely subjectively evaluated, visually, by volunteers and staff. Future work may examine if breed or developmental differences may impact survival in a shelter setting. Other work has not been able to link weight/size to survival in CPV [36,37], potentially due to the limited size and scope of their data. This study cannot fully assess the importance of weight, however, as the treatment protocols differ according to weight groups (see Appendix A for details). That being said, both in the anecdotal accounts of the veterinarians, staff, and volunteers as well as in the Treatment Data, we see a significant relationship between weight and survival that cannot be disregarded (in particular as the more extensive treatment is given to the population which survives less; i.e., low-weight animals). Future work should attempt to more carefully address this risk factor. Sex, on the other hand, showed similar male-biased mortality patterns (with an $8.6 \%$ difference) as has been previously observed both in CPV [37] as well as across huge varieties of species and ailments [60-62]. One final factor which was not examined in this study due to difficulty in diagnosis was the presence of comorbidities that might impact survival. Canine distemper, for example, often appears alongside CPV and can drastically reduce the chances of survival [2,63], though no direct study of this relationship is known by the authors. Special care is taken in the ICU to create air-breaks via plastic sheeting and variable risk isolation rooms to attempt to prevent these sorts of comorbidities, but outbreaks and singleton events can, and do, occur (though their frequency is difficult to assess given these data as only the exposure status, not the distemper symptoms, were tracked and no distemper tests were administered). Future work should more closely examine methods of reducing the spread of, especially, upper respiratory infections.

Although we believe the inferences discussed in this study are on firm statistical ground, some weaknesses in the data, including the lack of treatment-level resolution across the entire time range, gaps in some portions of the data set, and difficulty in measuring every variable that otherwise might be of interest, are worth consideration. Weight (in the Animal Records data; N = 1957; 2016-2020) was a particularly impoverished measure as weighing animals on intake has not always been standard practice. Continued data collection (especially given the significant improvements in shelter software systems in recent years) could help clarify some details in this study, such as if there is a second CPV season, if there are other trends in the survival of high-risk populations, and if there are efficiency gains that could be exploited to optimize treatments.

Finally, a few interesting future directions exist in treatment that should be examined in a shelter setting. Continuous $24 \mathrm{~h}$ monitoring via automated, low cost, noncontact medical devices [64], fecal transplants [65], antiviral treatments [66,67], blood transfusions [68], and more community outreach to encourage early intervention could potentially help save the last $10 \%-15 \%$ of animals in 
this population. Regardless of these innovations, together, these results demonstrate the imminently practical treatability of canine parvovirus in an animal shelter setting.

\section{Conclusions}

For most of the history of the canine parvovirus at the time of this publication, this disease has been a death sentence for infected dogs, whether due to its expense and difficulty in treatment, or due to the active euthanasia of animals with the infection by organizations fearing spread to the entire population. Although these fears are in some ways warranted, as CPV is incredibly contagious and deadly when left unchecked and untreated, by following the practices vetted over the last 10 years by Austin Pets Alive! (see Appendix A for details), shelters should expect to successfully save $>80 \%$ of CPV-infected animals in their care with little risk to their general populations. The total survival rate of animals during the 11.5-year period of this study was $86.6 \%(n=4438 / 5127$ dogs survived $)$ with the probability of survival increasing to $96.7 \%$ after five days of treatment. A distinct parvo season peaking in May and June and troughing in September and January was observed, which contributed as much as 41 animals peak-to-trough in the monthly population. Low-weight and male animals were at higher risk for death, whereas age was not a significant contributing factor. Further research should examine these high-risk populations to determine how to best provide them care, but canine parvovirus should now be viewed as imminently and practically treatable within the animal shelter setting.

Author Contributions: Conceptualization, E.J., K.H., and E.S.A.; methodology, K.H.; software, K.H.; validation, All Authors; formal analysis, K.H.; investigation, K.H.; resources, All Authors; data curation, K.H. and S.P.; writing-original draft preparation, K.H. and E.S.A.; writing-review and editing, All Authors; visualization, K.H.; supervision, E.J.; project administration, K.H.; funding acquisition, N/A. All authors have read and agreed to the published version of the manuscript.

Funding: This research received no external funding.

Acknowledgments: The authors would like to thank all the Austin Pets Alive! Parvo ICU Volunteers and Staff for all of their hard work and dedication over the past decade leading up to this publication. Additionally, all volunteers and staff at Austin Pets Alive!, our partners at Austin Animal Center, the City of Austin, and the greater Austin Community should be congratulated for their great work in pushing the state of the art and ethics of animal welfare forward over the past decade. Additionally, special thanks go to Elizabeth Davis for her notes and insightful statistical review, Nipuni Ratnayaka for her subject matter expertise and review, and Rory Adams for his contributions to the Research Committee goals.

Conflicts of Interest: The authors declare no conflict of interest. The funders of the treatments and operations of Austin Pets Alive! had no role in the design of the study; in the collection, analysis, or interpretation of data; in the writing of the manuscript, or in the decision to publish the results. Other components of this research were self-funded by volunteer researchers. Austin Pets Alive! and American Pets Alive! offers dogs who have survived parvovirus for adoption to the general public, but, as a nonprofit organization, are not financially incentivized to preferentially adopt these animals over others.

\section{Appendix A}

There are many aspects of the treatment of canine parvovirus and the operation of a Parvo Program which are beyond the scope of this work, but which can be found in the documentation hosted by Austin Pets Alive! at https://sites.google.com/site/parvowiki/. Best practices around running an isolation are within a shelter are particularly critical but will be left to the reader to explore in the expanded documentation. The core elements of the treatment protocol are enumerated here: 
Table A1. The treatment flow/logic that defines which of the three treatment protocols is followed for an individual dog. Note that four of the rows are not possible as there is a contradiction between being asymptomatic and having severe symptoms. Shading indicates various treatment times (dark-to-light: IV (Intravenous), SQ (Subcutaneous), and ET (Exposed Treatment)).

\begin{tabular}{ccccc}
\hline $\begin{array}{c}\text { Parvo Test } \\
\text { Result }\end{array}$ & $\begin{array}{c}\text { Is Animal } \\
\text { Symptomatic? }\end{array}$ & Is Weight $>\mathbf{5 ~ l b s ?}$ & $\begin{array}{c}\text { Blood Diarrhea, Pale Gums, } \\
\text { or Weak/Can't Stand? }\end{array}$ & $\begin{array}{c}\text { Treatment } \\
\text { Protocol }\end{array}$ \\
\hline Positive & Yes & Yes & Yes & IV \\
Positive & Yes & Yes & No \\
Positive & Yes & No & No & IV \\
Positive & Yes & No & No & IV \\
Positive & No & Yes & No & ET \\
Positive & No & No & Yes & SQ \\
Negative & Yes & Yes & No & IV \\
Negative & Yes & Yes & No & SQ \\
Negative & Yes & No & No & IV \\
Negative & Yes & No & No & SQ \\
Negative & No & Yes & & ET \\
\hline Negative & No & No & & \\
\hline
\end{tabular}

Appendix A.1. Intravenous (IV) Treatment Protocol

The following medications are given when animals are under the IV treatment protocol:

Table A2. Medications administered for IV treatment, their dose, route (subcutaneous, SQ; or oral, PO), and frequency (once a day, SID; twice a day, BID).

\begin{tabular}{ccccc}
\hline Medication Name & Dose & Route & Frequency & Notes \\
\hline Lactated Ringers $(\mathrm{LRS})$ & $22 \mathrm{~mL} / \mathrm{kg}$ & SQ & BID & \\
Enrofloxacin $(100 \mathrm{mg} / \mathrm{mL})$ & $0.11 \mathrm{~mL} / \mathrm{kg}$ & SQ & SID & Must be given with LRS \\
Ampicillin $(200 \mathrm{mg} / \mathrm{mL})$ & $0.11 \mathrm{~mL} / \mathrm{kg}$ & SQ & BID & \\
Metoclopramide $(5 \mathrm{mg} / \mathrm{mL})$ & $0.11 \mathrm{~mL} / \mathrm{kg}$ & SQ & BID & \\
Maropitant Citrate $(10 \mathrm{mg} / \mathrm{mL})$ & $0.045 \mathrm{~mL} / \mathrm{kg}$ & SQ & SID & \\
Fenbendazole $(100 \mathrm{mg} / \mathrm{mL})$ & $0.44 \mathrm{~mL} / \mathrm{kg}$ & PO & SID & For 5 days \\
\hline
\end{tabular}

Appendix A.2. Subcutaneous (SQ) Treatment Protocol

The following medications are given when animals are under the SQ treatment protocol:

Table A3. Medications administered for SQ treatment, their dose, route (subcutaneous, SQ; intravenous, IV; or oral, PO), and frequency (once a day, SID; twice a day, BID; continuous rate infusion, CRI).

\begin{tabular}{ccccc}
\hline Medication Name & Dose & Route & Frequency & Notes \\
\hline Lactated Ringers & $22 \mathrm{~mL} / \mathrm{kg}$ & SQ & SID & \\
Enrofloxacin $(100 \mathrm{mg} / \mathrm{mL})$ & $0.11 \mathrm{~mL} / \mathrm{kg}$ & SQ & SID & Must be given with LRS \\
Cefazolin $(250 \mathrm{mg} / \mathrm{mL})$ & $0.09 \mathrm{~mL} / \mathrm{kg}$ & IV & BID & Given slowly $(\sim 3 \mathrm{~min})$ \\
Metoclopramide $(5 \mathrm{mg} / \mathrm{mL})$ & $0.11 \mathrm{~mL} / \mathrm{kg}$ & SQ & Once & \\
Maropitant Citrate $(10 \mathrm{mg} / \mathrm{mL})$ & $0.09 \mathrm{~mL} / \mathrm{kg}$ & IV & SID & For 5 days \\
Fenbendazole $(100 \mathrm{mg} / \mathrm{mL})$ & $0.44 \mathrm{~mL} / \mathrm{kg}$ & PO & SID & Add $5 \%$ Dextrose if Blood Glucose \\
Lactated Ringers $(1 \mathrm{~L})+3 \mathrm{~mL}$ & & & & $<100$ or Weight $<5$ lbs \\
Metoclopramide $(5 \mathrm{mg} / \mathrm{mL})+$ & $7.3 \mathrm{~mL} / \mathrm{kg} / \mathrm{hr}$ & IV & CRI & \\
$20 \mathrm{mEq}$ Potassium Chloride & & & & \\
\hline
\end{tabular}

\section{Appendix A.3. Exposed Treatment (ET) Protocol}

The following medications are given when animals are under the ET treatment protocol. Note that animals under the ET protocol are attempted to be removed as soon as possible to be sent to a foster or other location. When possible, they are isolated from any symptomatic or positive animals. Scenarios 
in which animals test negative despite being admitted into the ICU are extremely rare, but they can occur under two circumstances. First, the animal may have tested positive at the originating facility, but negative at APA!. Second, the animal could have been part of an exposed litter that was tested as a group, but the individual later tested negative. In either case, the animal would have been euthanized at the originating shelter and is at sufficiently high risk of infection that they are isolated in the ICU and a protocol exists for their handling. Animals that proceed to at-home care (i.e., are not cared for in the ICU) are not counted towards the ICU numbers. Unfortunately, no extensive data exist for the relative success of the CPV test in use at APA!, but the IDEXX ELISA SNAP Parvo Test (the test in use for the entirety of the data covered by this study) claims to have $100 \%$ specificity and sensitivity (with 94\% and 89\% lower bounds on the 95\% confidence levels) [69]; however more recent studies have indicated that this could be drastically altered by strain and circumstance, resulting in a high incidence of false negatives (as poor as 50\%) [70-72]. Practitioners should carefully weigh examination of clinical condition and exposure status against negative test results when determining infection status.

Table A4. Medications administered for ET treatment, their dose, route (subcutaneous, SQ; or oral, PO), and frequency (once a day, SID; twice a day, BID).

\begin{tabular}{ccccc}
\hline Medication Name & Dose & Route & Frequency & Notes \\
\hline Ampicillin $(200 \mathrm{mg} / \mathrm{mL})$ & $0.05 \mathrm{~mL} / \mathrm{lb}$ & SQ & BID & \\
Fenbendazole $(100 \mathrm{mg} / \mathrm{mL})$ & $0.2 \mathrm{~mL} / \mathrm{lb}$ & PO & SID & For 5 days \\
\hline
\end{tabular}

\section{Appendix B}

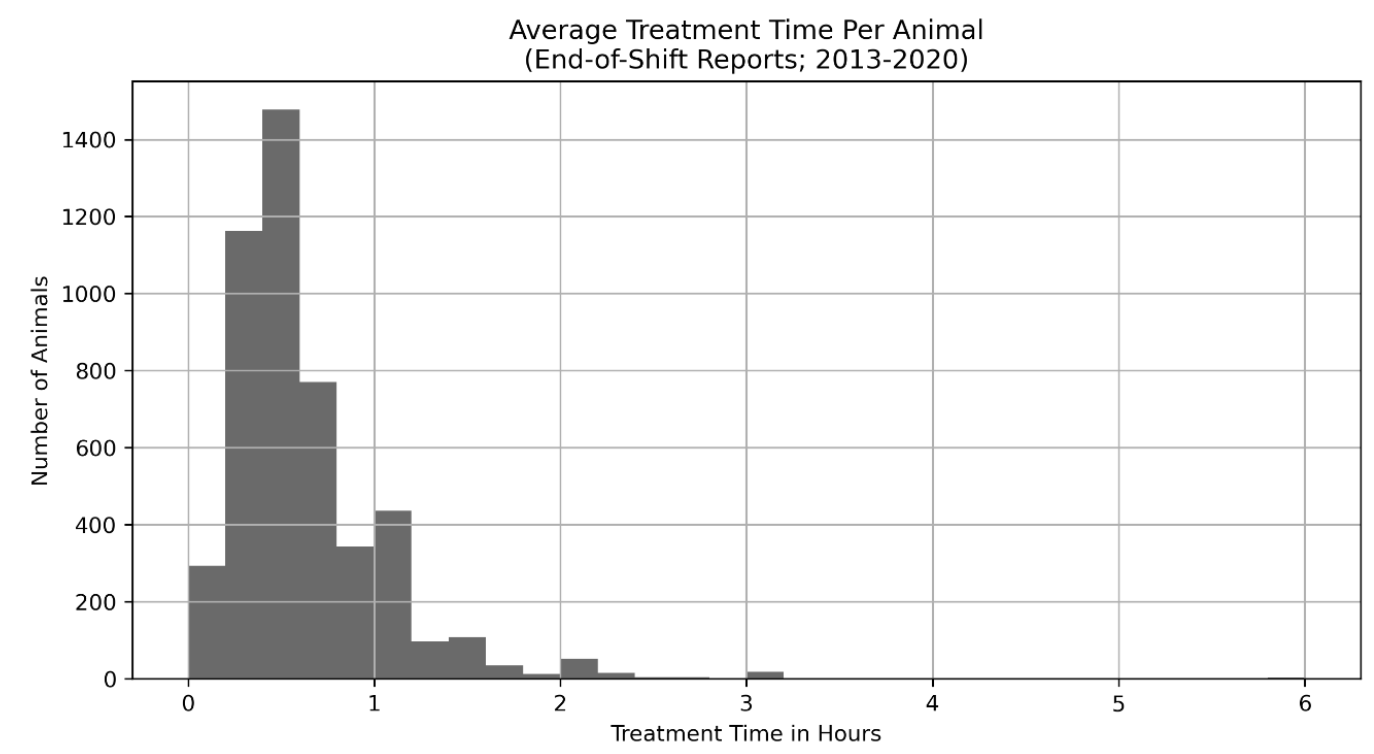

Figure A1. Distribution of average treatment times per dog per shift (per the End-of-Shift Reports; $\mathrm{N}$ days $=2474 ; 2013-2020$ ). The mean treatment time was $0.63 \mathrm{~h}$ per treatment. Two treatments per day were performed per animal. 


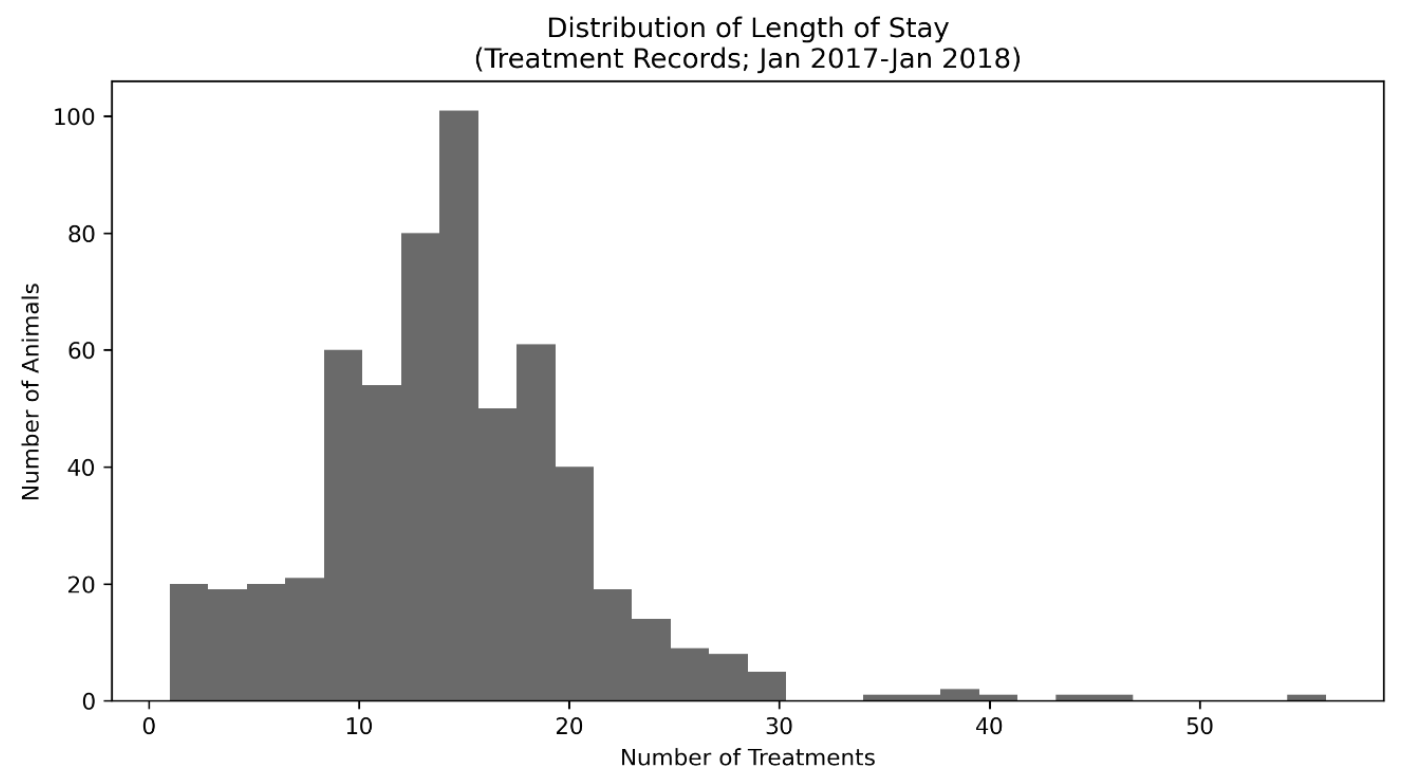

Figure A2. Distribution of length of stay of CPV-infected dogs (per the Treatment Records; $\mathrm{N}=589$; January 2017-January 2018). The length of stay was distributed around seven days. Note that the units on the horizontal axis are in treatments and there were two treatments per day.

\section{Appendix C}

Organizational structure and procedures are a key part of the success of a Parvo ICU. Although the complete details of operating an ICU of this sort are beyond the scope of this paper, certain key organization components are worth highlighting. Specifically, the roles of volunteers in the ICU (and their associated training), the critical supplies, including facilities, the isolation protocol, and crashing animal protocol are of critical importance to ensuring CPV infected animals can be successfully treated in mass.

\section{Appendix C.1. Organizational Structure, Volunteer Roles, and Treatment Shifts}

The Parvo ICU operated as a volunteer-only organization for the first year of its operation (including the Veterinary staff). Veterinary staff became the first paid position, followed by a group manager in 2013. Initially, volunteers were trained on all treatments, cleaning, and maintenance procedures and worked alone. By 2019, the program had anywhere from 20 to 40 volunteers (depending on season) and one to three staff members. The volunteer team split into a Medical and Care team to leverage individuals who might not want to participate in the extensive training required to become a Medical Treatment volunteer. Care team members were responsible for cleaning, feeding, laundry, dishes, and other ICU maintenance operations. Medical team members were responsible for all Care team duties as well as the medical treatment of all animals in the ICU.

The organization operates in a hierarchy such that the Veterinary staff dictate protocols, the manager and technician staff perform initial volunteer training, and the volunteers proceed to train one another and report to the manager and technician staff or Veterinarian if issues arise.

Treatment shifts generally last 2-3 h, beginning at 8 a.m. and 7 p.m. The ICU never closes unless no dogs are present. Veterinary staff adjust treatments daily, mid-day, and hired staff occupied the ICU during nonshift hours for cleaning purposes and to monitor for crashing animals.

\section{Appendix C.2. Supplies, Facilities, and Isolation Protocol}

In addition to medication listed in Appendix B and associated medical supplies, critical supplies included toilet paper, towels, soap/detergent, bleach, Trifectant broad-spectrum disinfectant, food (wet, dry, peanut butter, turkey/chicken, rice), bowls, and dog toys. All of these supplies were 
generally donated by local community members. Food was not consistently branded or typed and is stocked according to donations.

It is worth noting that prior to 2008, CPV infected animals in Austin were either left untreated, euthanized, or treated in the original "facility", a guest bathroom in the home of Dr. Ellen Jefferson, the Executive Director and, then, volunteer Veterinarian at APA!. APA!'s first official CPV ICU was a small, 1500 square foot storage area within APA!. The facility changed in 2013 from this smaller, private location to a former municipal shelter location, expanding the square footage significantly to 3500 square feet. The Parvo ICU was not a physically separated building, but it was isolated via doors and a changing room. The ICU was split into zones with dogs presenting with canine distemper symptoms being physically isolated in a separate zone from other animals. Litters were generally cohoused when possible.

Quarantine was maintained by requiring all volunteers and staff to change from street clothes into scrubs (which never left the ICU) upon entering the ICU and leave all belongings in lockers outside of the quarantine area. When exiting, all persons were required to wash hands, change clothes, step out of the quarantine area, wash hands again, and redress in street clothes.

\section{Appendix C.3. Shock/Crashing Animal Protocol}

Occasionally, animals would display signs associated with rapid deterioration of their condition and, potentially, shock. This typically included tacky, pale or white gums, cold extremities, convulsions, vocalization, thread pulse, inability to swallow, body temperature under 97 degrees, and coma/extreme lethargy. When one or more of these symptoms was observed, the following procedure was followed:

1. The animal is wrapped in a blanket immediately

2. $3 \mathrm{cc} / 101$ bs oral $50 \%$ Dextrose solution is administered every 3 min until resolution

3. The animal is positioned sternally if able

4. An IV catheter is placed if needed and an IV fluid bolus of $22 \mathrm{~mL} / \mathrm{kg}$ Lactated Ringers (if animal is less than or equal to three days in the ICU) or Hetastarch (if animal is more than three days in the ICU) is administered over $5-15 \mathrm{~min}$

5. Rectal temperature, blood glucose, packed cell volume, and total protein tests are run. The on-call Veterinarian is contacted

6. The animal is force fed once stabilized if not vomiting and water is added to future food served to the animal

7. The animal is placed on an IV pump per typical treatment protocols if not already present.

\section{References}

1. Miranda, C.; Thompson, G. Canine parvovirus: The worldwide occurrence of antigenic variants. J. Gen. Virol. 2016, 97, 2043-2057. [CrossRef] [PubMed]

2. Mylonakis, M.; Kalli, I.; Rallis, T. Canine parvoviral enteritis: An update on the clinical diagnosis, treatment, and prevention. Vet. Med. Res. Rep. 2016, 7, 91-100. [CrossRef] [PubMed]

3. Ford, J.; McEndaffer, L.; Renshaw, R.; Molesan, A.; Kelly, K. Parvovirus Infection Is Associated With Myocarditis and Myocardial Fibrosis in Young Dogs. Vet. Pathol. 2017, 54, 964-971. [CrossRef] [PubMed]

4. Otto, C.M.; Drobatz, K.J.; Soter, C. Endotoxemia and tumor necrosis factor activity in dogs with naturally occurring parvoviral enteritis. J. Veter- Intern. Med. 1997, 11, 65-70. [CrossRef]

5. N.A., Canine Parvovirus, AVMA. 2020. Available online: https://www.avma.org/resources-tools/pet-owners/ petcare/canine-parvovirus (accessed on 27 May 2020).

6. Kelman, M.; Ward, M.P.; Barrs, V.R.; Norris, J.M. The geographic distribution and financial impact of canine parvovirus in Australia. Transbound. Emerg. Dis. 2019, 66, 299-311. [CrossRef]

7. Osborne, D. Comparing fee guides. Can. Veter-J. = La Rev. Veter-Can. 2013, 54, 893-896. Available online: https://www.ncbi.nlm.nih.gov/pubmed/24155499 (accessed on 27 May 2020).

8. Brestrup, C. Disposable Animals: Ending the Tragedy of Throwaway Pets; Camino Bay Books: Kendalia, TX, USA, 1997; p. 78027, ISBN 978-0-9657285-9-1. 
9. Winograd, N. Redemption: The Myth of Pet Overpopulation and the No Kill Revolution in America, 2nd ed.; Almaden Books: Lexington, KY, USA, 2009; ISBN 978-0979074318.

10. Winograd, N. Irreconcilable Differences: The Battle for the Heart E Soul of America's Animal Shelters; CreateSpace Independent Publishing Platform: Scotts Valley, CA, USA, 2009; ISBN 978-1-4495-9113-7.

11. Winograd, N.; Jennifer, W. Friendly Fire; CreateSpace Independent Publishing Platform: Scotts Valley, CA, USA, 2012; ISBN 978-1479268931.

12. N.A., Parvo Puppy ICU, Austin Pets Alive! 2019. Available online: www.austinpetsalive.org/programs/ parvo-puppy-icu (accessed on 27 May 2020).

13. Horecka, K. The Last 10\%: Using Data Science to Save Parvo Puppies in Animal Shelters. Medium.com, 27 October 2018. Available online: medium.com/horecka-research/the-last-10-using-data-science-to-saveparvo-puppies-in-animal-shelters-f6abe74c20f6 (accessed on 27 May 2020).

14. Hawes, S.; Kerrigan, J.; Hupe, T.; Nawyn, T.; Morris, K.N. Estimating the Cost to Care for Animals at Austin Pets Alive! Maddie's Fund. 2020. Available online: https://www.maddiesfund.org/estimating-the-cost-tocare-for-animals-at-austin-pets-alive.htm (accessed on 27 May 2020).

15. Van Rossum, G. Python Tutorial; Technical Report CS-R9526; Centrum Voor Wiskunde en Informatica (CWI): Amsterdam, The Netherlands, May 1995.

16. Oliphant, T.E. Python for Scientific Computing. Comput. Sci. Eng. 2007, 9, 10-20. [CrossRef]

17. Millman, K.J.; Aivazis, M. Python for Scientists and Engineers. Comput. Sci. Eng. 2011, 13, 9-12. [CrossRef]

18. Travis, E. Oliphant. In A Guide to NumPy; CreateSpace Independent Publishing Platform: Scotts Valley, CA, USA, 2006.

19. Van Der Walt, S.J.; Colbert, S.C.; Varoquaux, G. The NumPy Array: A Structure for Efficient Numerical Computation. Comput. Sci. Eng. 2011, 13, 22-30. [CrossRef]

20. McKinney, W. Data Structures for Statistical Computing in Python. In Proceedings of the 9th Python in Science Conference, Austin, TX, USA, 28 June-3 July 2010; pp. 51-56.

21. Terpilowski, M. Scikit-posthocs: Pairwise multiple comparison tests in Python. J. Open Source Softw. 2019, 4, 1169. [CrossRef]

22. Davidson-Pilon, C.; Kalderstam, J.; Jacobson, N.; Zivich, P.; Kuhn, B.; Williamson, M.; Flaxman, A. CamDavidsonPilon/Lifelines: V0.24.4 (Version v0.24.4). Zenodo. 14 April 2020. Available online: http: //doi.org/10.5281/zenodo.3750430 (accessed on 27 May 2020).

23. Hunter, J.D. Matplotlib: A 2D Graphics Environment. Comput. Sci. Eng. 2007, 9, 90-95. [CrossRef]

24. Waskom, M.; Botvinnik, O.; O’Kane, D.; Hobson, P.; Lukauskas, S.; Gemperline, D.C.; Qalieh, A. Mwaskom/Seaborn: V0.8.1 (September 2017) (Version v0.8.1). Zenodo. 3 September 2017. Available online: http://doi.org/10.5281/zenodo.883859 (accessed on 27 May 2020).

25. Taylor, S.J.; Letham, B. Forecasting at scale. PeerJ Prepr. 2017, 5, e3190v2. [CrossRef]

26. Daniel Wayne, W. Kolmogorov-Smirnov one-sample test. In Applied Nonparametric Statistics, 2nd ed.; PWS-Kent: Boston, MA, USA, 1990; pp. 319-330, ISBN 978-0-534-91976-4.

27. Oosterbaan, R.J. Chapter 6 Frequency and Regression Analysis (PDF). In Drainage Principles and Applications; Ritzema, H.P., Ed.; Publication 16; International Institute for Land Reclamation and Improvement (ILRI): Wageningen, The Netherlands, 1994; pp. 175-224, ISBN 90-70754-33-9.

28. Kaplan, E.L.; Meier, P. Nonparametric estimation from incomplete observations. J. Amer. Statist. Assoc. 1958, 53, 457-481. [CrossRef]

29. Kaplan, E.L. In a retrospective on the seminal paper. In This Week's Citation Classic; Current Contents 24, University of Pennsylvania: Philadelphia, PA, USA, 1983; p. 14.

30. Kruskal, W. Use of ranks in one-criterion variance analysis. J. Am. Stat. Assoc. 1952, 47, 583-621. [CrossRef]

31. Stephens, M.A. Tests of Fit for the Logistic Distribution Based on the Empirical Distribution Function. Biometrika 1979, 66, 591-595. Available online: http://www.garfield.library.upenn.edu/classics1983/ A1983QS51100001.pdf (accessed on 27 May 2020). [CrossRef]

32. Bhargavi, M.; Shobhamani, B.; Kumari, K.N.; Srilatha, C. Therapeutic management of dogs affected with canine parvo virus (CPV) infection. Int. J. Sci. Environ. Technol. 2017, 6, 2797-2803. Available online: http://www.ijset.net/journal/1894.pdf (accessed on 27 May 2020).

33. Gaykwad, C.; Garkhal, J.; Chethan, G.E.; Nandi, S.; De, U.K. Amelioration of oxidative stress using $\mathrm{N}$-acetylcysteine in canine parvoviral enteritis. J. Veter-Pharmacol. Ther. 2018, 41, 68-75. [CrossRef] 
34. Khatri, R.; Poonam, M.H.; Minakshi, P.C. Epidemiology, Pathogenesis, Diagnosis and Treatment of Canine Parvovirus Disease in Dogs: A Mini Review. J. Veter-Sci. Med Diagn. 2017, 6, 06. [CrossRef]

35. Franzo, G.; Corso, B.; Tucciarone, C.M.; Drigo, M.; Caldin, M.; Cecchinato, M. Comparison and validation of different models and variable selection methods for predicting survival after canine parvovirus infection. Vet. Rec. 2020, 1-8. [CrossRef]

36. Iris Kalli Leontides, L.S.; Mylonakis, M.E.; Adamama-Moraitou, K.; Rallis, T.; Koutinas, A.F. Factors affecting the occurrence, duration of hospitalization and final outcome in canine parvovirus infection. Res. Vet. Sci. 2010, 89, 174-178. [CrossRef]

37. Pak, S.; Hwang, C.; Han, H. Prognostic factors for survival of dogs infected with canine parvovirus. Korean J. Vet. Res. 1999, 39, 838-845. Available online: http://file.newnonmun.com/kyobo_did-10837/200843.pdf (accessed on 27 May 2020).

38. Spindel, M.E.; Krecic, M.R.; Slater, M.R.; Vigil, N. Evaluation of a Community's Risk for Canine Parvovirus and Distemper Using Antibody Testing and GIS Mapping of Animal Shelter Intakes. J. Appl. Anim. Welf. Sci. 2018, 00, 1-13. [CrossRef] [PubMed]

39. N.A. Pearland Parvo Recovery Center. 2020. Available online: https://parvorecoverycenter.org/ (accessed on 27 May 2020).

40. N.A. Arizona Humane Society. Parvo Puppy ICU. 2020. Available online: https://www.azhumane.org/sickinjured-animals/parvo-puppy-icu/ (accessed on 27 May 2020).

41. Markovich, J.E.; Stucker, K.M.; Carr, A.H.; Harbison, C.E.; Scarlett, J.M.; Parrish, C.R. Effects of canine parvovirus strain variations on diagnostic test results and clinical management of enteritis in dogs. J. Am. Vet. Med. Assoc. 2012, 241, 66-72. [CrossRef] [PubMed]

42. Otto, C.M.; Jackson, C.B.; Rogell, E.J.; Prior, R.B.; Ammons, W.S. Recombinant bactericidal/permeability -increasing protein (rBPI21) for treatment of parvovirus enteritis: A randomized, double-blinded, placebocontrolled trial. J. Vet. Intern. Med. 2001, 15, 355-360. Available online: https:/www.ncbi.nlm.nih.gov/ pubmed/11467593 (accessed on 27 May 2020). [CrossRef] [PubMed]

43. Glickman, L.T.; Domanski, L.M.; Patronek, G.J.; Visintainer, F. Breed-related risk factors for canine parvovirus enteritis. J. Am. Vet. Med Assoc. 1985, 187, 589-594. Available online: https://www.ncbi.nlm.nih.gov/pubmed/ 3003015 (accessed on 27 May 2020).

44. Berg, B. "Hurricane HARVEY". National Hurricane Center. NOAA. 2018. Available online: https: //www.nhc.noaa.gov/archive/2017/al09/a1092017.update.08241656.shtml (accessed on 27 May 2020).

45. Stambaugh, M.C.; Creacy, G.; Sparks, J.; Rooney, M. Three centuries of fire and forest vegetation transitions preceding Texas' most destructive wildfire: Lost Pines or lost oaks? For. Ecol. Manag. 2017, 396, 91-101. [CrossRef]

46. Ahmed, S. Investigation of the Antiviral effect of Acyclovir on Canine Parvovirus Infection. Pharm. Pharmacol. Int. J. 2015, 2, 2-6. [CrossRef]

47. Behdenna, A.; Lembo, T.; Calatayud, O.; Cleaveland, S.; Halliday, J.E.B.; Packer, C.; Viana, M. Transmission ecology of canine parvovirus in a multi-host, multi-pathogen system. Proc. Biol. Sci. 2019, 286, 20182772. [CrossRef]

48. Houston, D.M.; Ribble, C.S.; Head, L.L. Risk factors associated with parvovirus enteritis in dogs: 283 cases (1982-1991). J. Am. Vet. Med. Assoc. 1996, 208, 542-546. Available online: http://www.ncbi.nlm.nih.gov/ pubmed/8603904 (accessed on 27 May 2020).

49. LA County. Canine Parvovirus in Dogs-Epidemiology Update. 1, 7060. 2015. Available online: https: //admin.publichealth.lacounty.gov/vet/reports/2015CanineParvoEpiQ3.pdf (accessed on 27 May 2020).

50. Shima, F.K.; Apaa, T.T.; Mosugu, J.I.T. Epidemiology of Canine Parvovirus Enteritis among Hospitalized Dogs in Effurun/Warri Metropolitan Region of Delta State, Nigeria. OALib 2015, 2, 1-7. [CrossRef]

51. Stann, S.E.; DiGiacomo, R.F.; Giddens, W.E.; Evermann, J.F. Clinical and pathologic features of parvoviral diarrhea in pound-source dogs. J. Am. Vet. Med Assoc. 1984, 185, 651-655. Available online: http: //www.ncbi.nlm.nih.gov/pubmed/6092314 (accessed on 27 May 2020). [PubMed]

52. Altizer, S.; Dobson, A.; Hosseini, P.; Hudson, P.; Pascual, M.; Rohani, P. Seasonality and the dynamics of infectious diseases. Ecol. Lett. 2006, 9, 467-484. [CrossRef] [PubMed]

53. Martinez, M.E. The calendar of epidemics: Seasonal cycles of infectious diseases. PLoS Pathog. 2018, 14, 1-15. [CrossRef] [PubMed] 
54. Gordon, J.C.; Angrick, E.J. Canine parvovirus: Environmental effects on infectivity. Am. J. Vet. Res. 1986, 47, 1464-1467. Available online: http://www.ncbi.nlm.nih.gov/pubmed/3017161 (accessed on 27 May 2020). [PubMed]

55. Clegg, S.R.; Coyne, K.P.; Dawson, S.; Spibey, N.; Gaskell, R.M.; Radford, A.D. Canine parvovirus in asymptomatic feline carriers. Vet. Microbiol. 2012, 157, 78-85. [CrossRef] [PubMed]

56. Duscher, G.G.; Leschnik, M.; Fuehrer, H.P.; Joachim, A. Wildlife reservoirs for vector-borne canine, feline and zoonotic infections in Austria. Int. J. Parasitol. 2015, 4, 88-96. [CrossRef]

57. De Cramer, K.G.M.; Stylianides, E.; van Vuuren, M. Efficacy of vaccination at 4 and 6 weeks in the control of canine parvovirus. Vet. Microbiol. 2011, 149, 126-132. [CrossRef]

58. Nandi, S.; Kumar, M. Canine parvovirus: Current perspective. Indian J. Virol. 2010, 21, 31-44. [CrossRef]

59. Pandya, M.S.; Sharma, K.K.; Kalyani, H.I.; Sakhare, S.P. Study on Host Predisposing Factors and Diagnostic Tests for Canine Parvovirus (CPV-2) Infection in Dogs. J. Anim. Res. 2017, 7, 897. [CrossRef]

60. Alberts, S.C.; Archie, E.A.; Gesquiere, L.R.; Altmann, J.; Vaupel, J.W.; Christensen, K. The Male-Female Health-Survival Paradox: A Comparative Perspective on Sex Differences in Aging and Mortality. In Sociality, Hierarchy, Health: Comparative Biodemography: A Collection of Papers; National Academies Press: Washington, DC, USA, 2014. Available online: https://www.ncbi.nlm.nih.gov/books/NBK242444/ (accessed on 27 May 2020).

61. Crimmins, E.M.; Shim, H.; Zhang, Y.S.; Kim, J.K. Differences between Men and Women in Mortality and the Health Dimensions of the Morbidity Process. Clin. Chem. 2019, 65, 135-145. [CrossRef]

62. Regitz-Zagrosek, V. Sex and gender differences in health. Science \& Society Series on Sex and Science. EMBO Rep. 2012, 13, 596-603. [CrossRef] [PubMed]

63. Martella, V.; Elia, G.; Buonavoglia, C. Canine Distemper Virus. Veter-Clin. N. Am. Small Anim. Pract. 2008, 38, 787-797. [CrossRef] [PubMed]

64. Lampe, R. Are You Breathing? Non-Contact Respiratory Rate Monitoring of Resting Dogs. Royal Veterinary College. 2014. Available online: http://www.live.ac.uk/Media/LIVE/PDFs/respiratoryRate_final_RLampe.pdf (accessed on 27 May 2020).

65. Pereira, G.Q.; Gomes, L.A.; Santos, I.S.; Alfieri, A.F.; Weese, J.S.; Costa, M.C. Fecal microbiota transplantation in puppies with canine parvovirus infection. J. Vet. Intern. Med. 2018, 32, 707-711. [CrossRef] [PubMed]

66. Zhou, H.; Su, X.; Lin, L.; Zhang, J.; Qi, Q.; Guo, F.; Yang, B. Inhibitory Effects of Antiviral Drug Candidates on Canine Parvovirus in F81 cells. Viruses 2019, 11, 742. [CrossRef] [PubMed]

67. Judge, P. Management of the Patient with Canine Parvovirus Enteritis. Vet Educ. 2015, 21, 5-11. Available online: https://www.nzvna.org.nz/site/nzvna/files/Quizzes/Parvo.pdf (accessed on 27 May 2020).

68. Decaro, N.; Campolo, M.; Desario, C.; Elia, G.; Martella, V.; Lorusso, E.; Buonavoglia, C. Maternally-derived antibodies in pups and protection from canine parvovirus infection. Biologicals 2005, 33, 261-267. [CrossRef]

69. Schultz, R.D.; Larson, L.J.; Lorentzen, L.P. Effects of modified live canine parvovirus vaccine on the SNAP ELISA antigen assay. In Proceedings of the International Veterinary Emergency Critical Symposium, Phoenix, AZ, USA, 18-21 September 2008. Available online: https://www.idexx.com/files/snap-parvo-test-accuracy.pdf (accessed on 27 May 2020).

70. Desario, C.; Decaro, N.; Campolo, M.; Cavalli, A.; Cirone, F.; Elia, G.; Martella, V.; Lorusso, E.; Camero, M.; Buonavoglia, C. Canine parvovirus infection: Which diagnostic test for virus? J. Virol. Methods 2005, 126, 179-185. [CrossRef]

71. Proksch, A.L.; Unterer, S.; Speck, S.; Truyen, U.; Hartmann, K. Influence of clinical and laboratory variables on faecal antigen ELISA results in dogs with canine parvovirus infection. Vet. J. 2015, 204, 304-308. [CrossRef]

72. Faz, M.; Martínez, J.S.; Quijano-hernández, I.; Fajardo, R. Reliability of clinical diagnosis and laboratory testing techniques currently used for identification of canine parvovirus enteritis in clinical settings. J. Vet. Med. Sci. 2017, 79, 213-217. [CrossRef]

(C) 2020 by the authors. Licensee MDPI, Basel, Switzerland. This article is an open access article distributed under the terms and conditions of the Creative Commons Attribution (CC BY) license (http://creativecommons.org/licenses/by/4.0/). 